\title{
High Value Activated Carbons from Waste Polystyrene Foams
}

Fabiano G. F. de Paula ${ }^{a}$, Mateus C. M. de Castro ${ }^{a}$, Paulo F. R. Ortega ${ }^{b}$ Clara Blanco $^{c}$, Rodrigo L. Lavall ${ }^{\mathrm{a}}$ and Ricardo Santamaría ${ }^{\mathrm{c} *}$

a. Departamento de Química/ICEx - Universidade Federal de Minas Gerais. Av. Antônio Carlos, 6627 - Pampulha, CEP 31270-901, Belo Horizonte - MG, Brazil

b. Centro Federal de Educação Tecnológica de Minas Gerais - Campus IV. Av. Ministro Olavo Drummond, 25 - São Geraldo, CEP 38180-510, Araxá - MG, Brazil

c. Instituto Nacional del Carbón, INCAR-CSIC, Apdo. 73, 33080-Oviedo, Spain

\begin{abstract}
Activated carbons (AC) with excellent textural properties have been obtained for the first time from waste polystyrene foam (PF), without any previous treatment, following a simple and conventional two-step procedure (formation of char followed by chemical activation). Even considering that the PF is not a graphitizable material, the best AC produced from this precursor has a very high BET surface area larger than $2700 \mathrm{~m}^{2} \mathrm{~g}^{-1}$ and a pore volume of $1.2 \mathrm{~cm}^{2} \mathrm{~g}^{-1}$, with a significant contribution of small mesopores. As a consequence, this $\mathrm{AC}$ reveals a surprising capacity to adsorption of relatively large molecules and a high specific capacitance when applied as a supercapacitor electrode. The maximum amount of adsorbed methylene blue obtained by batch equilibrium experiments are greater than $1 \mathrm{~g} \mathrm{~g}^{-1}$. In the context of the technical difficulties and low economic return of the reuse and recycling of waste PF, this work offers a strategic destination for this environmentally unfriendly residue.
\end{abstract}

*Corresponding author. E-mail address: riqui@incar.csic.es (R. Santamaría) 


\section{Introduction}

Activated carbons are commonly used products that have been produced from a large number of different precursors, which may be mineral, biological or synthetic [13]. Increasing concern about sustainability in our society is encouraging the production of re-usable materials obtained not from natural resources but from waste $[4,5]$. Millions of tons of plastic waste are discarded each year, most of which is either incinerated or dumped in landfills [6]. Many efforts have been made by researchers to use these wastes as feedstock for the production of value-added products, such as fuels, high added-value carbons (e.g. carbon nanotubes) or large surface area carbons [6-9]. In recent years there has been considerable research in the area of activated carbon production from plastic wastes, as a result of which products with large surface areas and pore volumes have been obtained [6]. A survey was recently published on the use of various plastics to produce activated carbons with special focus on the use of PET [6, 7].

Polystyrene (PS) is an abundant plastic material (with annual production estimated at about 2.95 million tons) that generates a very appreciable volume of waste [10]. PS is produced in a variety of solid and foams and it is used in several applications. As an example, the expanded polystyrene foam (EPF) is frequently employed as packaging for different goods [11]. Unfortunately, this material is difficult to recycle and their reuse or recycling has little business interest due to low economic return $[11,12]$.

Different forms of polystyrene have been used to produce activated carbons, not as precursor material but as sacrificial hard template to obtain hollow spherical sludge carbon [13], or as a thin film over magnesium oxide to obtain a porous carbon film [14], or a copyrolysis agent together with biomass [15] or as a catalyst support [16]. It is 
important to note that to date no attempts to directly convert this material into activated carbon have been reported. Wang et al. used polystyrene-based macro-reticular ionexchange resin spheres, which is a copolymer of polystyrene and divinylbenzene functionalized with sulfuric acid, as precursor [17, 18]. During the pyrolysis/carbonization, the $\mathrm{C}-\mathrm{C}$ linking bonds between the monomers break releasing small molecules and aromatic hydrocarbons which are distilled from the system. The use of copolymers or structure modifications (acidic pre-oxidation) strengthens the link between the monomers favoring the aromatization reactions and the formation of char [19]. Otherwise, only liquid and gas products are obtained in the polystyrene pyrolysis [20]. In this study, this problem is solved by using a simple two-step conventional process where first char is produced from waste polystyrene foams (PF) under Ar pressure to maintain the volatile compounds in the system until their total aromatization. Then, the char obtained is chemically activated to yield ACs with a very large surface area and high adsorption capacity. Finally, the produced ACs were characterized by several techniques and their adsorption capacity was measured using methylene blue (MB) as model molecule. Also, the electrochemical performance of these materials was tested for their application as electrodes in supercapacitors.

\section{Experimental}

Initially, waste EPF without any previous treatment was used as precursor for the production of char. $10 \mathrm{~g}$ of EPF that was first dissolved in acetone and then dried by means of a hot air gun, was introduced into a vertical furnace and pyrolyzed at a relatively low temperature $\left(530{ }^{\circ} \mathrm{C}\right)$, at a heating rate of $10^{\circ} \mathrm{C} \mathrm{min}-1$ and under Ar at a pressure of 10 bar for $5 \mathrm{~h}$. Acetone was only used to reduce the polymer volume, as air bubbles are removed from the expanded polymer. Thereby, the amount of PF carbonized per batch is increased. 
In a second step the char thus produced (PF-Char) was subjected to chemical activation using anhydrous $\mathrm{KOH}$ as activation agent, with a $\mathrm{KOH}$ to $\mathrm{PF}-\mathrm{Char}$ ratio of 4:1. Three activated carbons (ACs) were prepared by applying different activation temperatures $\left(600,700\right.$ and $\left.800^{\circ} \mathrm{C}\right)$ in a horizontal furnace for $1 \mathrm{~h}$. After this process, the products were washed in a $10 \% \mathrm{HCl}$ solution and then in distilled water in a Soxhlet apparatus until a pH 7 was obtained.

The textural characteristics of the carbon materials were obtained from their $\mathrm{N}_{2}$ isotherms at $77 \mathrm{~K}$, which were carried out in a Micromeritics ASAP 2420. The C, N and $\mathrm{H}$ content were quantified from the combustion (at $1050{ }^{\circ} \mathrm{C}$ ) of $1 \mathrm{mg}$ of the corresponding sample by means of a LECO-CHNS-932 microanalyzer. The total oxygen content of the samples was determined directly in a LECO-TF-900 furnace coupled to the previous equipment. The electrical conductivity was measured on the shaped discs prepared by mixing $90 \mathrm{wt} \%$ of the carbon material and $10 \mathrm{wt} \%$ of polytetrafluoroethylene using a four-point probe system (Keithley Instruments, Model 238 High Current Source Measure Unit, USA). SEM images were obtained using a field emission gun scanning electron microscope (QUANTAN FEG 650, FEI) operating at 5 $\mathrm{kV}$. TEM observations were performed on a JEOL $2000 \mathrm{EX}-\mathrm{II}$ instrument operating at $160 \mathrm{keV}$. Suspensions of ACs were deposited on standard holey carbon copper grids using the drop cast method and loaded into the microscope.

MB adsorption tests were performed by introducing $20 \mathrm{~mL}$ of MB solution (2.0 M) into tubes which contained $15 \mathrm{mg}$ of each $\mathrm{AC}$. The tubes were shaken and placed vertically in a thermostatically controlled bath in the absence of light at $298.15 \mathrm{~K}$ for 24 h. The amount of adsorbed MB was directly calculated from the difference between the initial and final concentrations in the supernatant. These concentrations were determined 
by absorption measurements $(663 \mathrm{~nm})$ using a Shimadzu spectrometer UV-2550 (Japan).

The electrochemical performance of the ACs was studied on pellet type electrodes prepared by pressing a mixture of AC (90 wt.\%) and PVDF (10 wt.\%). The mass of each electrode was about $30 \mathrm{mg}$. Supercapacitors were built with glass fiber separators and gold current collectors, using a "T-type" Swagelok ${ }^{\circledR}$ cell. To record the potentials of the electrodes, a $\mathrm{Ag} / \mathrm{AgCl} / 3.5 \mathrm{M} \mathrm{KCl}$ reference electrode was used as a third-end connection and the tests were performed in $1 \mathrm{M} \mathrm{H}_{2} \mathrm{SO}_{4}$. The electrochemical measurements tests were carried out at ambient temperature in a BioLogic VMP Muiltichannel Potentiostat/Galvanostat.

\section{Results and discussion}

The $\mathrm{N}_{2}$-adsorption/desorption isotherms obtained for AC600, AC700 and AC800 are presented in Fig. 1(A). All the ACs show type 1 isotherms (IUPAC system [21]), characteristic of microporous materials. The highest temperature $\left(800^{\circ} \mathrm{C}\right)$ favored the formation of a material with a wider pore size distribution (PSD), as indicated by the wide knee observed in the isotherm. The PSD calculated by QSDFT corroborates these results (Fig. 1(B)), as it can be seen that the $\mathrm{AC}$ obtained at $800{ }^{\circ} \mathrm{C}$ has pore diameters within the range of supermicropores and even a small proportion of narrow mesopores.

Fig. 1(A) and 1(B)

The main textural parameters of the ACs are summarized in Table 1. The BET surface areas are in all cases larger than $2000 \mathrm{~m}^{2} \mathrm{~g}^{-1}$ and increase with the activation temperature to over $2700 \mathrm{~m}^{2} \mathrm{~g}^{-1}$ in the activated carbon obtained at $800{ }^{\circ} \mathrm{C}$. A similar trend was observed for the pore volume. Sample AC800 shows the largest pore volume 
$\left(1.2 \mathrm{~cm}^{3} \mathrm{~g}^{-1}\right)$ with a very significant contribution of mesoporosity $\left(0.27 \mathrm{~cm}^{3} \mathrm{~g}^{-1}\right)$. The mesopore contribution to the pore volume is 2.5 higher than in the AC600 sample.

\section{Table 1}

From the mesopore volume contribution (Table 1) and the DFT curves, that in the case of AC800 show a significant contribution of supermicropores, it can be inferred that this carbon would be especially suitable for the adsorption of large molecules, such MB used here as model molecule. The maximum amounts adsorbed by AC600, AC700 and AC800 were 270, 536 and $1042 \mathrm{mg} \mathrm{g}^{-1}$ respectively. The $\mathrm{AC}$ obtained at $800{ }^{\circ} \mathrm{C}$ evidenced an excellent adsorption performance with an outstanding amount of MB adsorbed, one of the highest, in fact, ever published in the literature (Table 2) [23-33].

\section{Table 2}

Other non-carbon materials are known for their good adsorption properties. Metal organic frameworks (MOF's) reach adsorption values for MB close to the results presented above [31]. Yet, compared to the ACs production, MOFs synthesis is usually more expensive and time consuming. In addition, Zeolites and Mobil Composition of Matters (MCM) adsorption capacity of MB do not reach the values found in this study $[32,33]$.

Increasing the activation temperature also affects the chemical composition of the carbon materials and, therefore, their surface chemistry. Table 3 shows the elemental compositions and electrical resistivity for the different ACs studied. It is worth noting that the functional group content of the activated carbons decreases drastically with an increase of $200{ }^{\circ} \mathrm{C}$ in the activation temperature. At $600{ }^{\circ} \mathrm{C}$ the oxygen content remains rather high $(13.2 \%)$ since the oxidation of the carbon material progress slowly and some intermediate oxidation species still remain in the carbon. Higher temperatures favor the decomposition of these groups (which are eliminated in the form of $\mathrm{CO}$ or $\mathrm{CO}_{2}$ ) 
resulting in a decrease in the oxygen content and in a further development of the porosity.

\section{Table 3}

The samples were further characterized by means of SEM and TEM. Images corresponding to sample AC800 are shown in Fig. 2.

\section{Fig. 2(A) and 2(B)}

SEM studies indicate the presence of large particle $(<200 \mu \mathrm{m})$ and a good population of smaller particles, all of which have smooth surfaces. TEM studies evidence the typical highly disordered structure of non-graphitizable carbons, with small individual layers that are twisted, bent and randomly arranged, resulting in the high surface area measured by nitrogen adsorption. Nevertheless, although TEM does not show any significant changes in the structural arrangement of these samples, it is known that activated carbons obtained at higher temperature present a more organized structure, as has been demonstrated by Ruiz et al. [34], probably due to the loss of oxygen and a low-range structural rearrangement. This is reflected in the electrical resistivity $(\rho)$, which is also an important property for materials to be used in energy storage devices. For the samples under study it varies from more than $1000 \Omega \mathrm{cm}$ for AC600 to just $5.5 \Omega \mathrm{cm}$ for AC800 (Table 3).

To exemplify the potential use of these ACs in energy storage, symmetrical supercapacitors were constructed with these materials derived from PF. The best result is obtained with AC800 due to its highest $S_{B E T}$ and low resistivity. The specific capacitance achieved by this electrode exceeds $250 \mathrm{~F} \mathrm{~g}^{-1}$, values similar to those obtained with the best electrodes based on mesophase-derived activated carbon [34]. The electrochemical properties for all cells constructed in this work are summarized in the supporting information (Fig. S1 and Table S1). 
The excellent adsorption results obtained for MB envisages a good adsorption for other dyes and pharmaceutical contaminant molecules that resembles the MB molecule size and structure [35]. Also, adsorption/storage of gases such as methane and $\mathrm{CO}_{2}$ has a great dependence on the adsorbents microporosity volume, suggesting another possible application for these materials [36, 37]. Furthermore, our process does not differ considerably from the conventional process that is already used in industry for the production of ACs with high surface areas, that is, pyrolysis of the precursor followed by chemical activation using $\mathrm{KOH}$ [38]. In comparison to the process described in this paper, the major difference is that pressure is used during pyrolysis. Therefore, although PF is a non-graphitizable material, ACs synthesized from this precursor presents outstanding physicochemical properties, with equal or even better results than most of the graphitizable precursors offering an interesting destination for waste PF $[4,24,39,40]$.

\section{Conclusion}

In conclusion, activated carbons with very remarkable properties have been obtained for the first time from waste-expanded polystyrene foam, offering a new alternative for the recycling of this environmentally unfriendly residue. The surface area of the activated carbon produced from $\mathrm{PF}$ at $800{ }^{\circ} \mathrm{C}$ exceeded $2700 \mathrm{~m}^{2} \mathrm{~g}^{-1}$ and the relatively wide microporosity/small mesopososity showed a great ability to adsorb organic molecules like MB (1042 $\left.\mathrm{mg} \mathrm{g}^{-1}\right)$. The best material activated at $800{ }^{\circ} \mathrm{C}$ still presents low resistivity and is strategic as supercapacitor electrodes, reaching specific capacitance values of $250 \mathrm{~F} \mathrm{~g} \mathrm{~g}^{-1}$. Finally, with these results we hope to leverage the attention of specialists and encourage the use of waste PF to produce ACs on large 
scales in place of other precursors with less environmental appeal. This could also be a possible and simple solution to add value to the recycling of this material.

\section{Acknowledgments}

The authors would like to thank the Conselho Nacional de Desenvolvimento Científico e Tecnológico $(\mathrm{CNPq})$ - Brazil for the financial support (PVE 2014, process number 400714/2014-0). Fabiano G. F. de Paula and Paulo F. R. Ortega also acknowledge CAPES and CNPq for the received scholarships, respectively. Financial support from Ministerio de Economía, Industria y Competitividad (project MAT2016-77114-R) and Principado de Asturias (Fondo Europeo de Desarrollo Regional (GRUPIN 14-118).

\section{References}

[1] J.F. Kwiatkowski, Activated carbon: classifications, properties and applications, first ed., Nova Science Publishers, New York, 2012.

[2] M. Plaza-Recobert, G. Trautwein, M. Perez-Cadenas, J. Alcaniz-Monge, Preparation of binderless activated carbon monoliths from cocoa bean husk, Micropor. Mesopor. Mater 243 (2017) 28-38.

[3] S.J. Li, K.H. Han, J.X. Li, M. Li, C.M. Lu, Preparation and characterization of super activated carbon produced from gulfweed by $\mathrm{KOH}$ activation, Micropor. Mesopor. Mater 243 (2017) 291-300.

[4] A.S. Al-Rahbi, P.T. Williams, Production of activated carbons from waste tyres for low temperature NOx control, Waste Manag. 49 (2016) 188-195.

[5] M. Acikyildiz, A. Gurses, S. Karaca, Preparation and characterization of activated carbon from plant wastes with chemical activation, Micropor. Mesopor. Mater 198 (2014) 45-49. 
[6] A. Bazargan, C.W. Hui, G. McKay, in: T.E. Long, B. Voit, O. Okay, (Eds.), Porous Carbons - Hyperbranched Polymers - Polymer Solvation, Springer, Berlin, 2015, pp. 125.

[7] M. Adibfar, T. Kaghazchi, N. Asasian, M. Soleimani, Conversion of Poly(Ethylene Terephthalate) Waste into Activated Carbon: Chemical Activation and Characterization, Chem. Eng. Technol. 37 (2014) 979-986.

[8] S. Kumar, A.K. Panda, R.K. Singh, A review on tertiary recycling of high-density polyethylene to fuel, Resour. Conserv. Recy. 55 (2011) 893-910.

[9] J.B. Parra, C.O. Ania, A. Arenillas, F. Rubiera, J.J. Pis, High value carbon materials from PET recycling, Appl. Surf. Sci. 238 (2004) 304-308.

[10] Merchant Research \& Consulting, Expandable Polystyrene (EPS): 2017 World Market Outlook and Forecast up to 2027, UK, 2017.

[11] J. Savoldelli, D. Tomback, H. Savoldelli, Breaking down polystyrene through the application of a two-step thermal degradation and bacterial method to produce usable byproducts, Waste Manag. 60 (2017) 123-126.

[12] T. Maharana, Y.S. Negi, B. Mohanty, Review article: Recycling of polystyrene, Polym. Plast. Technol. Eng. 46 (2007) 729-736.

[13] Z.J. Wu, L.J. Kong, H. Hu, S.H. Tian, Y. Xiong, Adsorption Performance of Hollow Spherical Sludge Carbon Prepared from Sewage Sludge and Polystyrene Foam Wastes, ACS Sustainable Chem. Eng. 3 (2015) 552-558.

[14] Y.L. Wen, J. Liu, J.F. Song, J. Gong, H. Chen, T. Tang, Conversion of polystyrene into porous carbon sheets and hollow carbon shells over different magnesium oxide templates for efficient removal of methylene blue, RSC Adv. 5 (2015) 105047-105056. 
[15] E. Lorenc-Grabowska, P. Rutkowski, High Adsorption Capacity Carbons from Biomass and Synthetic Polymers for the Removal of Organic Compounds from Water, Water, Air, Soil Pollut. 225 (2014).

[16] C.H. You, S.J. Liao, X.C. Qiao, X.Y. Zeng, F.F. Liu, R.P. Zheng, H.Y. Song, J.H. Zeng, Y.W. Li, Conversion of polystyrene foam to a high-performance doped carbon catalyst with ultrahigh surface area and hierarchical porous structures for oxygen reduction, J. Mater. Chem. A 2 (2014) 12240-12246.

[17] Q. Wang, X. Liang, W. Qiao, C. Liu, X. Liu, L. Zhan, L. Ling, Preparation of polystyrene-based activated carbon spheres with high surface area and their adsorption to dibenzothiophene, Fuel Process. Technol. 90 (2009) 381-387.

[18] Q. Wang, X. Liang, R. Zhang, C. Liu, X. Liu, W. Qiao, L. Zhan, L. Ling, Preparation of polystyrene-based activated carbon spheres and their adsorption of dibenzothiophene, New Carbon Mater. 24 (2009) 55-60.

[19] L. Gonsalvesh, S.P. Marinov, G. Gryglewicz, R.Carleer, J.Yperman, Preparation, characterization and application of polystyrene based activated carbons for $\mathrm{Ni}$ (II) removal from aqueous solution, Fuel Process. Technol. 149 (2016) 75-85.

[20] N. Kiran, E. Ekinci, C.E. Snape, Recyling of plastic wastes via pyrolysis, Resour. Conserv. Recycl. 29 (2000) 273-283.

[21] M. Thommes, K. Kaneko, A.V. Neimark, J.P. Olivier, F. Rodriguez-Reinoso, J. Rouquerol, K.S.W. Sing, Physisorption of gases, with special reference to the evaluation of surface area and pore size distribution (IUPAC Technical Report), Pure Appl. Chem. 87 (2015) 1051-1069.

[22] A.M. Carvajal-Bernal, F. Gomez, L. Giraldo, J.C. Moreno-Pirajan, Adsorption of phenol and 2,4-dinitrophenol on activated carbons with surface modifications, Micropor. Mesopor. Mater 209 (2015) 150-156. 
[23] D. Barreda, A.M. Perez-Mas, A. Silvestre-Albero, M.E. Casco, S. Rudic, C. Herdes, E.A. Muller, C. Blanco, R. Santamaria, J. Silvestre-Albero, F. RodriguezReinoso, Unusual flexibility of mesophase pitch-derived carbon materials: An approach to the synthesis of graphene, Carbon, 115 (2017) 539-545.

[24] Y. Li, Q. Du, T. Liu, X. Peng, J. Wang, J. Sun, Y. Wang, S. Wu, Z. Wang, Y. Xia, L. Xia, Comparative study of methylene blue dye adsorption onto activated carbon, graphene oxide, and carbon nanotubes, Chem. Eng. Res. Des. 91 (2013) 361-368.

[25] L.H. Ai, C.Y. Zhang, F. Liao, Y. Wang, M. Li, L.Y. Meng, J. Jiang, Removal of methylene blue from aqueous solution with magnetite loaded multi-wall carbon nanotube: Kinetic, isotherm and mechanism analysis, J. Hazard. Mater 198 (2011) 282290.

[26] P.F.R. Ortega, J.P.C. Trigueiro, M.R. Santos, A.M.L. Denadai, L.C.A. Oliveira, A.P.C. Teixeira, G.G. Silva, R.L. Lavall, Thermodynamic Study of Methylene Blue Adsorption on Carbon Nanotubes Using Isothermal Titration Calorimetry: A Simple and Rigorous Approach, J. Chem. Eng. Data 62 (2017) 729-737.

[27] K. Legrouri, E. Khouya, M. Ezzine, H. Hannache, R. Denoyel, R. Pallier, R. Naslain, Production of activated carbon from a new precursor molasses by activation with sulphuric acid, J. Hazard. Mater. 118 (2005) 259-263.

[28] A. Gücek, S. Şener, S. Bilgen, M.A. Mazmanc1, Adsorption and kinetic studies of cationic and anionic dyes on pyrophyllite from aqueous solutions, J. Colloid Interface Sci. 286 (2005) 53-60.

[29] K. Sui, Y. Li, R. Liu, Y. Zhang, X. Zhao, H. Liang, Y. Xia, Biocomposite fiber of calcium alginate/multi-walled carbon nanotubes with enhanced adsorption properties for ionic dyes, Carbohydr. Polym. 90 (2012) 399-406. 
[30] M.A. Al-Ghouti, M.A.M. Khraisheh, S.J. Allen, M.N. Ahmad, The removal of dyes from textile wastewater: a study of the physical characteristics and adsorption mechanisms of diatomaceous earth, J. Environ. Manage. 69 (2003) 229-238.

[31] M. Oveisi, M.A. Asli, N.M. Mahmoodi, MIL-Ti metal-organic frameworks (MOFs) nanomaterials as superior adsorbents: Synthesis and ultrasound-aided dye adsorption from multicomponent wastewater systems, J. Hazard. Mater. 347 (2018) 123-140.

[32] A.K. Hammed, N. Dewayanto, D. Du, M.H. Ab Rahim, M.R. Nordin, Novel modified ZSM-5 as an efficient adsorbent for methylene blue removal, J. Environ. Chem. Eng. 4 (2016) 2607-2616.

[33] S. Sohrabnezhad, A. Pourahmad, Comparison absorption of new methylene blue dye in zeolite and nanocrystal zeolite, Desalination 256 (2010) 84-89.

[34] V. Ruiz, C. Blanco, E. Raymundo-Pinero, V. Khomenko, F. Beguin, R. Santamaria, Effects of thermal treatment of activated carbon on the electrochemical behaviour in supercapacitors, Electrochim. Acta 52 (2007) 4969-4973.

[35] P. González-García, Activated carbon from lignocellulosics precursors: A review of the synthesis methods, characterization techniques and applications, Renew. Sust. Energ. Rev. 82 (2018) 1393-1414.

[36] M.E. Casco, M. Martínez-Escandell, K. Kaneko, J. Silvestre-Albero, F. RodríguezReinoso, Very high methane uptake on activated carbons prepared from mesophase pitch: A compromise between microporosity and bulk density, Carbon, 93 (2015) 1121.

[37] M.E. Casco, M. Martínez-Escandell, J. Silvestre-Albero, F. Rodríguez-Reinoso, Effect of the porous structure in carbon materials for $\mathrm{CO} 2$ capture at atmospheric and high-pressure, Carbon, 67 (2014) 230-235. 
[38] K.H.J. Buschow, Encyclopedia of Materials: Science and Technology v.10, first ed., Elsevier, USA, 2001.

[39] Z.K. Chowdhury, R.S. Summers, G.P. Westerhoff, B.J. Leto, K.O. Nowack, C.J. Corwin, L.B. Passantino, Activated Carbon: Solutions for Improving Water Quality, first ed., American Water Works Association, US, 2013.

[40] Y.X. Li, X. Zhang, R.G. Yang, G.Y. Li, C.W. Hu, Removal of dyes from aqueous solutions using activated carbon prepared from rice husk residue, Water Sci. Technol. 73 (2016) 1122-1128.

Table 1. Textural parameters for the ACs obtained at different activation temperatures.

\begin{tabular}{ccccc}
\hline Material & $\begin{array}{c}\boldsymbol{S}_{\text {BET }} \\
\left(\mathbf{m}^{\mathbf{2}} \mathbf{g}^{\mathbf{- 1}}\right)\end{array}$ & $\begin{array}{c}\mathbf{V}_{\text {total }} \\
\left(\mathbf{c m}^{\mathbf{3}} \mathbf{g}^{\mathbf{- 1}}\right)\end{array}$ & $\begin{array}{c}\mathbf{V}_{\text {micro }} \\
\left(\mathbf{c m}^{\mathbf{3}} \mathbf{g}^{-\mathbf{1}}\right)\end{array}$ & $\begin{array}{c}\mathbf{V}_{\text {meso }} \\
\left(\mathbf{c m}^{\mathbf{3}} \mathbf{g}^{\mathbf{- 1}}\right)\end{array}$ \\
\hline AC600 & 2109 & 0.88 & 0.77 & 0.11 \\
AC700 & 2315 & 0.96 & 0.84 & 0.12 \\
AC800 & 2712 & 1.2 & 0.93 & 0.27
\end{tabular}

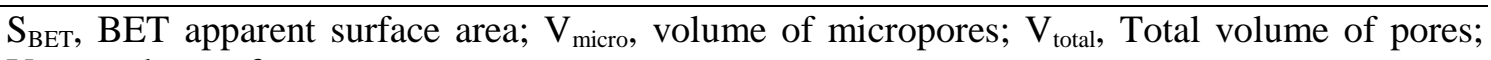
$\mathrm{V}_{\text {meso }}$, volume of mesopores

Table 2. Previously reported adsorption capacities of various adsorbents for methylene blue.

\begin{tabular}{ccc}
\hline Adsorbent & Adsorption capacity $\left(\mathbf{m g ~ g}^{-1}\right)$ & Ref. \\
\hline Graphene oxide & 243.9 & {$[24]$} \\
Carbon nanotubes & 99.8 & {$[26]$} \\
Activated carbon & 435 & {$[27]$}
\end{tabular}


Mesophase pitch-derived AC

Pyrophyllite

Calcium alginate/MWCNTs

Diatomite

MOF [ $\left.\mathrm{NH}_{2}-\mathrm{MIL}-125(\mathrm{Ti})\right]$

Zeolite (NZVI/SuZSM)

606.1

156.6

862

87,0

AC800

1042.0

Table 3. Elemental composition and electrical resistivity for the ACs obtained at different activation temperatures.

\begin{tabular}{cccccc}
\hline Material & $\mathbf{C}(\mathbf{w t} \%)$ & $\mathbf{H}(\mathbf{w t} \%)$ & $\mathbf{N}(\mathbf{w t} \%)$ & $\mathbf{O}(\mathbf{w t} \%)$ & $\boldsymbol{\rho}(\mathbf{\Omega} \mathbf{~ m})$ \\
\hline AC600 & 86.65 & 0.76 & 0.14 & 13.18 & 1045.09 \\
AC700 & 90.83 & 0.43 & 0.13 & 8.35 & 63.64 \\
AC800 & 94.36 & 0.22 & 0.17 & 3.83 & 5.52 \\
\hline
\end{tabular}

\section{Figure captions:}

Fig. 1. (A) $\mathrm{N}_{2}$ adsorption-desorption isotherm at $77 \mathrm{~K}$ up to 1 bar for the AC materials.

(B) Pore size distribution by applying Quenched Solid Density Functional Theory analysis to the $\mathrm{N}_{2}$ adsorption-desorption isotherm (QSDFT) for the three materials.

Fig. 2. SEM (A) and TEM (B) images of AC800. 